\title{
Model for Inclusion Precipitation Kinetics During Solidification of Steel Applications in MnS and TiN Inclusions
}

\author{
QIFENG SHU, VILLE-VALTTERI VISURI, TUOMAS ALATARVAS, \\ and TIMO FABRITIUS
}

\begin{abstract}
A simulation model for inclusion precipitation kinetics during solidification of steel was proposed in this work. With the aim to calculate the inclusion size distribution during solidification of steel, the microsegregation calculation combined with the Kampmann-Wagner numerical $(\mathrm{KWN})$ model for nucleation and growth of inclusion was incorporated into the present simulation model for calculating the evolution of inclusion size distribution during solidification of steel. The inclusion agglomeration due to Brownian collisions was also taken into account. The present simulation model was first applied in simulating precipitation of $\mathrm{MnS}$ during steel solidification and validated by the experimental data available in the literature. The effects of cooling rates and sulfur concentrations on the precipitation of $\mathrm{MnS}$ were investigated by the model calculations. Then, the present simulation model was applied in simulating the precipitation of TiN inclusions during steel solidification. The calculated mean size was found to be in good agreement with data available in the literature. Finally, the model was employed for studying the effects of interfacial tension between TiN and steel due to sulfur concentration change and cooling rates on the inclusion precipitation kinetics. It was found that interfacial tension between TiN and steel has a crucial influence on the precipitation of TiN. With an increase of the cooling rate, the size distribution of TiN transforms from the lognormal distribution to the bimodal distribution.
\end{abstract}

https://doi.org/10.1007/s11663-020-01955-0

(c) The Author(s) 2020

\section{INTRODUCTION}

NonMeTALLIC inclusions in steel are detrimental to properties of steel products, such as strength, toughness, fatigue strength, and surface quality. ${ }^{[1]}$ Solid inclusions can also gradually deposit on the wall of a submerged entry nozzle and eventually cause its clogging. Therefore, one of the most important tasks for steelmakers is to control the inclusion formation during steelmaking and continuous casting. Exogenous inclusions mainly originate from wearing of refractory and the entrapment of slag. ${ }^{[1]}$ Most endogenous inclusions are generated by the deoxidation of steel during secondary metallurgy. ${ }^{[1-3]}$ Owing to the supersaturation of segregated elements in the interdendritic liquid, some new oxide and sulfide inclusions precipitate from steel during continuous casting; these could be called

QIFENG SHU, VILLE-VALTTERI VISURI, TUOMAS ALATARVAS, and TIMO FABRITIUS are with the Process Metallurgy Research Unit, University of Oulu, 90014 Oulu, Finland. Contact email: qifeng.shu@oulu.fi

Manuscript submitted March 21, 2020.

Article published online September 21, 2020. "secondary endogenous inclusions." The secondary inclusions are typically small, but sometimes they can be harmful to the properties of steel. Therefore, it is also important to control the composition, size, and spatial distribution of inclusions during solidification to achieve a better quality of steel.

Many experimental investigations have been performed on the inclusion formation during solidification. ${ }^{[4-9]}$ Sui et al. ${ }^{[6]}$ investigated the growth of sulfides in free-cutting stainless steel and found that sulfide inclusions are coarsened during the slow cooling and heat treatment process due to Ostwald ripening. Suzuki et al. ${ }^{[8]}$ investigated the inclusion particles in continuously cast stainless steel slab and laboratory-scale ingot casting steel. They found that an Ostwald ripening model provided the best correlation with experimental data.

There have been many attempts to model the formation of inclusion by combining microsegregation with thermodynamics. ${ }^{[10-14]}$ Various segregation models ${ }^{[15-19]}$ have been employed to calculate the element enrichments in residual liquid due to the rejection from dendrites during solidification. The formation of inclusions due to the supersaturation of solutes was further 
calculated in an equilibrium manner. To this end, commercial thermodynamic tools, e.g., FactSage and ChemApp, have frequently been applied. ${ }^{[11-13]}$

A thermodynamic model for inclusion formation during solidification provides only the information of equilibrated inclusion composition. The inclusion size distribution can be calculated only by a kinetic model considering the nucleation, growth, and coarsening phenomena. Only a few models ${ }^{[20-24]}$ dealing with kinetics of inclusion formation have been proposed in the literature. Rocabois et al. ${ }^{[20]}$ developed a model coupling nucleation, mixed-controlled growth, and microsegregation to calculate the precipitation kinetics of TiN during solidification. Their microsegregation calculation is oversimplified and size distribution could not be obtained from their model. Recently, You et $a .^{[23]}$ developed a comprehensive kinetic model to simulate $\mathrm{MnS}$ formation during solidification of steel. However, they have to introduce an adjustable parameter for collision to fit with experimental data. Besides, they did not consider the coarsening of inclusions due to Ostwald ripening.

Based on a theory by Langer and Schwartz, ${ }^{[25]}$ Kampmann and Wagner ${ }^{[26]}$ treated nucleation, growth, and coarsening as couple processes by using a framework suitable for numerical calculation. The Kampmann-Wagner numerical (KWN) model has been extensively applied in estimating phase precipitation. ${ }^{[27-32]}$ However, so far, this model has not been applied for modeling inclusion formation during solidification.

In the present work, a kinetic model for inclusion evolution during solidification combining the microsegregation calculation with the $\mathrm{KWN}$ model was proposed to calculate the evolution of inclusion size distribution during the solidification of steel. The model was validated by the experimental data of precipitations of manganese sulfide and titanium nitride inclusions during the solidification of steel.

\section{MODEL DESCRIPTIONS}

The present model combines the microsegregation calculation with the kinetic model for nucleation, growth, and agglomeration of inclusions. The following assumptions are made in the present model for the sake of simplification

(1) During microsegregation calculations, the equilibrium partition coefficients between solid and liquid are assumed to be constant during solidification.

(2) Only one kind of inclusion was assumed to be precipitated from liquid during solidification and only homogenous nucleation is taken into consideration for precipitation of inclusions during solidification.

(3) The morphology of inclusion particles during nucleation, growth, and agglomeration is assumed to be spherical. ${ }^{[2,23,33,34]}$

(4) The interfacial tension between inclusion and steel remains the same for inclusion particles of all sizes.
The Gibbs-Thomson equation pertains to inclusion particles of all sizes.

(5) The growth and coarsening of inclusion particles is assumed to be controlled by the diffusion from the bulk steel phase to the interface between inclusion and steel.

There are many submodels employed to finally fulfil the aim of the present simulation model. First, the compositions for interdendritic liquids at various temperatures were calculated by using a stepwise form of the Ohnaka $^{[17]}$ model. Then, the compositions were employed as inputs for a kinetic model for nucleation, growth, and agglomeration of inclusions. The nucleation and growth of inclusions was simulated by employing the $\mathrm{KWN}^{[26]}$ model. The agglomeration was modeled using the population balance equation (PBE), which is solved by the particle size grouping (PSG) method. The submodels are described in detail as follows.

\section{A. Microsegregation Model}

Ohnaka ${ }^{[17]}$ presented a segregation model to calculate the concentrations of solute in residual liquid during solidification. You et al. ${ }^{[15]}$ modified Ohnaka's model into stepwise form as follows:

$$
\begin{aligned}
& C_{L}^{+}=C_{L}\left\{\frac{1-\Gamma \cdot f_{s}}{1-\Gamma \cdot\left(f_{s}+\Delta f_{s}\right)}\right\}^{\frac{1-k}{\Gamma}} \\
& \text { with } \Gamma=1-\frac{4 \alpha k}{1+4 \alpha} \text { and } \alpha=\frac{4 D t_{f}}{\left(\lambda_{2}\right)^{2}}
\end{aligned}
$$

where $f_{s}$ is the solidification fraction; $C_{L}^{+}$and $C_{L}$ are the concentrations of the solutes in the residual liquid at the solidification fraction of $f_{s}$ and $f_{s}+\Delta f_{s}$, respectively; $D$ is the diffusion coefficient of solute in solid solution; $\lambda_{2}$ is secondary dendrite arm spacing (SDAS); $k=C_{S} / C_{L}$ is the equilibrium partition coefficient between solid and liquid during solidification; and $t_{f}$ is local solidification time and can be calculated by the following equation:

$$
t_{f}=\frac{T_{L}-T_{S}}{C R}
$$

where $T_{L}$ and $T_{S}$ are the liquidus and solidus temperature for steel, respectively (in Celsius), and $C R$ is the cooling rate.

Won and Thomas ${ }^{[35]}$ compiled the data for the diffusion coefficients of solutes in solid solution and the equilibrium partition coefficients of elements between solid and liquid during solidification. The data related to the present study are listed in Table I.

There are several correlations of liquidus and solidus temperature with steel compositions in the literature. In this work, the correlations presented by Diederichs and Bleck $^{[36]}$ are employed to calculate the liquidus and solidus temperature (in Celsius) as follows: 
Table I. Data for the Diffusion Coefficient of Solute in Solid Solution and the Equilibrium Partition Coefficient between Solid and Liquid during Solidification ${ }^{[12,35]}$

\begin{tabular}{lcccc}
\hline & \multicolumn{2}{c}{$\delta$ Phase } & \multicolumn{2}{c}{$\gamma$ Phase } \\
\cline { 2 - 4 } Element & $k$ & $D \times 10^{4}\left(\mathrm{~m}^{2} / \mathrm{s}\right)$ & $k$ & $D \times 10^{4}\left(\mathrm{~m}^{2} / \mathrm{s}\right)$ \\
\hline Mn & 0.77 & $0.76 \exp (-224,430 / R T)$ & 0.785 & $0.055 \exp (-249,366 / R T)$ \\
S & 0.05 & $4.56 \exp (-214,639 / R T)$ & 0.035 & $2.4 \exp (-223,426 / R T)$ \\
$\mathrm{C}$ & 0.19 & $0.0127 \exp (-81,379 / R T)$ & 0.34 & $0.15 \exp (-143,511 / R T)$ \\
$\mathrm{Ti}$ & 0.38 & $3.15 \exp (-247,693 / R T)$ & 0.33 & $0.15 \exp (-250,956 / \mathrm{R} T)$ \\
$\mathrm{N}$ & 0.25 & $0.008 \exp (-79,078 / R T)$ & 0.48 & $0.91 \exp (-168,490 / R T)$ \\
\hline
\end{tabular}

$$
\begin{aligned}
T_{L}= & 1536-83[\text { pct } \mathrm{C}]-31.5[\text { pct } \mathrm{S}]-32[\text { pct } \mathrm{P}] \\
& -5[\text { pct } \mathrm{Mn}+\text { pct } \mathrm{Cu}]-7.8[\text { pct Si }] \\
& -3.6[\text { pct } \mathrm{Al}]-1.5[\text { pct } \mathrm{Cr}]-2[\text { pct } \mathrm{Mo}] \\
& -4[\text { pct Ni }]-18[\text { pct Ti }]-2[\text { pct } \mathrm{V}]
\end{aligned}
$$

The solid fraction could be calculated by temperature at the solidification front using the following equation $^{[14]}$ :

$$
f_{s}=\frac{\left(T_{L}-T\right)\left(1536-T_{S}\right)}{(1536-T)\left(T_{L}-T_{S}\right)}
$$

where $T$ is the temperature at the solidification front of steel (in Celsius).

The application of the microsegregation model requires the data of SDAS for various steel grades. Several correlations of SDAS with steel compositions were proposed in the literature based on measurements. Won and Thomas ${ }^{[35]}$ critically reviewed the correlation and experimental data and proposed the following equations for steel with a wide range of carbon contents:

When $0<$ [pct $\mathrm{C}]<0.15$,

$$
\lambda_{2}=\left(169.1-720.9 C_{0}\right) \mathrm{CR}^{-0.4935}
$$

When [pet C] $>0.15$,

$$
\lambda_{2}=143.9 C_{0}^{\left(0.5501-1.996 C_{0}\right)} \mathrm{CR}^{-0.3616}
$$

where $\lambda_{2}$ represents SDAS $(\mu \mathrm{m}), C_{0}$ represents the carbon concentration (in mass percentage) in steel, and $C R$ represents the cooling rate (in ${ }^{\circ} \mathrm{C} / \mathrm{s}$ ).

\section{B. Thermodynamics of Inclusion Formation}

\section{Precipitation of sulfide}

During the solidification of steel, sulfur is often heavily segregated. The reaction for precipitation of manganese sulfide during solidification of steel is often considered:

$$
[\mathrm{Mn}]+[\mathrm{S}]=(\mathrm{MnS})
$$

The solubility product $K_{\mathrm{MnS}}$ is given by ${ }^{[23,37]}$

$$
\log _{10} K_{\mathrm{MnS}}=\log ([\mathrm{Mn} \text { pct }][\mathrm{S} \text { pct }])=-\frac{8750}{T}+4.63
$$

\section{Precipitation of nitrides}

Precipitation of titanium nitrides occurs during solidification of Ti-stabilized stainless steel or other steel grades containing Ti. The reaction can be represented by

$$
[\mathrm{Ti}]+[\mathrm{N}]=(\mathrm{TiN})
$$

The solubility product $K_{\mathrm{TiN}}$ is given by ${ }^{[38]}$

$$
\log _{10} K_{\mathrm{TiN}}=\log ([\text { Tipct }][\text { Npct }])=-\frac{14,400}{T}+4.94
$$

\section{KWN Model}

\section{Basic equations}

The nucleation of inclusion could follow the way of homogenous or heterogeneous nucleation. In this work, for the sake of simplification, only homogenous nucleation is taken into consideration for precipitation of inclusions during cooling. Thus, the steady-state nucleation rate $I$ can be expressed as ${ }^{[39]}$

$$
I=\mathrm{I}_{\mathrm{A}} \exp \left(\frac{\Delta G_{\mathrm{hom}}^{*}}{\mathrm{k}_{\mathrm{b}} T}\right)
$$

where $I_{\mathrm{A}}$ is a pre-exponential factor, $k_{\mathrm{b}}$ is the Boltzmann constant, and $\Delta G_{\text {hom }}^{*}$ is the free energy barrier for homogeneous nucleation and can be calculated as

$$
\Delta G_{\mathrm{hom}}^{*}=\frac{16 \pi \sigma^{3}}{3 \Delta G_{V}^{2}}
$$

where $\sigma$ is the interfacial tension between inclusion and residue steel liquid and $\Delta G_{V}$ is Gibbs free energy change per molar volume for inclusion formation.

The crystals would undergo growth or dissolution depending on whether the interfacial concentration is larger than the matrix concentration. The rate for growth or dissolution can be calculated as follows: ${ }^{[40]}$ 


$$
v=\frac{\mathrm{d} r}{\mathrm{~d} t}=\frac{\bar{C}-C_{i}}{C_{\mathrm{P}}-C_{i}} \frac{D}{r}
$$

where $\bar{C}$ is the concentration in residue liquid steel, $C_{p}$ is the concentration in inclusion, $C_{i}$ is the concentration at the interface, $D$ is the diffusion coefficient of the element in liquid steel, and $r$ is the radius of the inclusion.

The concentration at the inclusion-steel interface could be calculated from equilibrium concentration $C_{e}$ by the Gibbs-Thomson equation:

$$
C_{i}=C_{e} \exp \left(\frac{2 \sigma V_{m}}{r \mathrm{R} T}\right)
$$

where $\sigma$ is the interfacial tension between inclusion and residue steel liquid and $V_{m}$ is the molar volume of inclusion.

Through Eqs. [12] and [13], both growth and coarsening of inclusion particles can be modeled. The critical size $r^{*}$ for the transition from dissolution to growth can be calculated by combining Eqs. [12] and [13]:

$$
r^{*}=\frac{2 \sigma V_{m}}{\mathrm{R} T\left(\ln \left(\frac{\bar{C}}{C_{e}}\right)\right)}
$$

\section{Numerical methods}

Myhr and Grong ${ }^{[32]}$ proposed a control volume approach to calculate the particle size distribution using the Kampmann-Wagner theory. Particle size distribution was discretized into a series of small radius elements, which could be treated as control volumes according to the definition and terminology used by Patankar. ${ }^{[41]}$ Following the method by Myhr and Grong, ${ }^{[32]}$ in this work, the total size distribution was discrete into a series of radius elements $r_{i}$ with width of $\Delta r_{i}$. The radius for each element increases by a constant factor of $R_{r}$ compared with the previous neighbor element. According to the classic grid configuration for the control volume method in CFD, the grids employed in the present study are shown in Figure 1. If we use the up-wind scheme by Patankar, ${ }^{[41]}$ the following discrete equations can be obtained for calculation of number density at grid $\mathrm{P}$ from the number densities at grids $\mathrm{P}, \mathrm{W}$ (west), and $\mathrm{E}$ (east) in the last iteration:

$$
N_{\mathrm{P}}=N_{\mathrm{P}}^{0}+\Delta N_{\mathrm{W}}+\Delta N_{\mathrm{E}}
$$

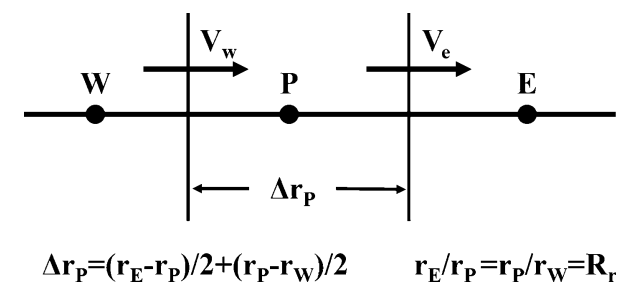

Fig. 1-Grid configuration in the present model.
$v_{\mathrm{W}}>0$ :

$$
\Delta N_{\mathrm{W}}=N_{\mathrm{W}}^{0} v_{\mathrm{W}} \Delta t / \Delta r_{\mathrm{W}}
$$

$v_{\mathrm{W}}<0$ :

$$
\Delta N_{\mathrm{W}}=N_{\mathrm{P}}^{0} v_{\mathrm{W}} \Delta t / \Delta r_{\mathrm{P}}
$$

$v_{\mathrm{E}}>0$ :

$$
\Delta N_{\mathrm{E}}=N_{\mathrm{P}}^{0} v_{\mathrm{E}} \Delta t / \Delta r_{\mathrm{P}}
$$

$v_{\mathrm{E}}<0$ :

$$
\Delta N_{\mathrm{E}}=N_{\mathrm{E}}^{0} v_{\mathrm{E}} \Delta t / \Delta r_{\mathrm{E}}
$$

where $N_{\mathrm{P}}$ denotes the present number density at the $\mathrm{P}$ grid; $N_{\mathrm{P}}^{0}, N_{\mathrm{W}}^{0}$, and $N_{\mathrm{E}}^{0}$ denote the number densities at $\mathrm{P}, \mathrm{W}$, and $\mathrm{E}$ grids before iteration, respectively; $\Delta t$ is the time-step; and $\Delta r_{\mathrm{W}}, \Delta r_{\mathrm{P}}$, and $\Delta r_{\mathrm{E}}$ are the radius width for $\mathrm{W}, \mathrm{P}$, and $\mathrm{E}$ grids, respectively. $v_{\mathrm{W}}$ and $v_{\mathrm{E}}$ are the rates of growth and dissolution for grids $\mathrm{W}$ and $\mathrm{E}$.

The mass conservation law enables us to calculate the matrix solute concentration in interdendritic liquid steel after the inclusion precipitation:

$$
\bar{C}=\frac{C_{0}-C_{\mathrm{p}} \frac{\rho_{\mathrm{st}}}{\rho_{\mathrm{p}}} V_{\mathrm{p}}}{1-\frac{\rho_{\mathrm{st}}}{\rho_{\mathrm{p}}} V_{\mathrm{p}}}, \quad \text { with } V_{\mathrm{p}}=\sum_{i=1}^{\infty} \frac{4}{3} \pi r_{i}^{3} N_{i}
$$

where $C_{p}$ represents the solute concentration in inclusions; $C_{0}$ is the initial solute concentration in interdendritic liquid steel; $\rho_{\text {st }}$ and $\rho_{\mathrm{P}}$ represent the density of liquid steel and inclusion, respectively; and $V_{\mathrm{p}}$ is the total volume of inclusions.

In the residual liquid during solidification, there also could be some agglomeration of inclusions due to collisions. In the ladle treatment and tundish, different collisions, including Brownian, stokes, and turbulent collisions, were considered in modeling the behavior of inclusions. ${ }^{[33,34,42]}$ However, in intradendritic liquid during casting, the velocity of liquid cannot be easily determined, but it can be assumed that the turbulence of liquid is weak due to the lack of strong stirring. Especially for some types of inclusions (e.g., MnS), which are only precipitated at very high solidification fraction, the motion of inclusions is rather limited. Accordingly, only agglomeration due to Brownian collision was accounted for in the present work.

The well-known PBE was employed to describe the agglomeration of inclusions in residual liquid ${ }^{[43]}$.

$$
\frac{\mathrm{d} n_{k}}{\mathrm{~d} t}=\frac{1}{2} \sum_{i=i_{c}, i+j=k}^{k-i_{c}} \beta_{i j}^{C} n_{i} n_{j}-\sum_{i=1}^{\infty} \beta_{i k}^{C} n_{i} n_{k}
$$

where the Brownian collision frequency function $\beta_{i j}^{B}$ can be represented by

$$
\beta_{i j}^{B}=\frac{2 \mathrm{k}_{\mathrm{B}} T}{3 \mu}\left(\frac{1}{r_{i}}+\frac{1}{r_{j}}\right)\left(r_{i}+r_{j}\right)
$$


The PSG method ${ }^{[42]}$ is an efficient method to solve the PBE. According to this method, the particles can be divided into $M$ groups. The size of particles in each group is increasing by $R_{r}$ times compared with the size of particles in the previous group. The following equation could be obtained to replace the PBE:

$$
\begin{aligned}
\frac{\mathrm{d} n_{k}}{\mathrm{~d} t}= & \sum_{i=i_{c, k-1}}^{k-1} \xi_{i, k-1} \beta_{i j}^{C} n_{i} n_{k-1}+\sum_{i=1}^{i_{c, k-1}} \xi_{i, k} \beta_{i j}^{C} n_{i} n_{k} \\
& -\sum_{i=i_{c, k}}^{N-1}\left(1+\delta_{i k}\right) \beta_{i j}^{C} n_{i} n_{k}
\end{aligned}
$$

where $n_{i}$ denotes the number density of group $i$ and $i_{c, k}$ denotes the critical size number, which was determined by the $R_{r}$ ratio. When $R_{r}=2^{1 / 3}$, $i_{c, k}=k-1 . \xi_{i, k-1}$ and $\xi_{i, k}$ are the correction factors and can be calculated as follows:

$$
\begin{gathered}
\xi_{i, k-1}=\left(v_{i}+v_{k-1}\right) / v_{k} \\
\xi_{i, k}=v_{i} / v_{k}
\end{gathered}
$$

where $v_{\mathrm{i}}$ denotes the volume of particle in group $i$.

\section{Inclusion Behavior at Solidification Interface}

At the solid-liquid steel interface, the inclusions can be engulfed by the solid steel or pushed into the residual liquid. A critical solidification velocity above which the inclusion would be engulfed was defined in previous modeling and experimental work. ${ }^{[44,45]}$ In these studies, inclusions were often assumed to be engulfed in solidified steel. Yamada et al. ${ }^{[46]}$ assumed that inclusions at the solidification front are completely captured by the solid. The inclusions were distributed homogenously in liquid and the amount of captured inclusion could be calculated by the solidification step. You et al. ${ }^{[11,23]}$ employed this method to calculate the distribution of inclusions in solid and residual liquid steel.

In this work, we consider two situations: engulfment and pushing of inclusions, depending on the cooling conditions. For validation of the MnS model, the engulfment of inclusions was assumed since the cooling rate is high $\left(>13{ }^{\circ} \mathrm{C} / \mathrm{s}\right)$. In contrast, the pushing of inclusions was assumed for validation of the TiN model due to the low cooling rate of $0.37{ }^{\circ} \mathrm{C} /$ s. In the case of engulfment, we use the same method to distribute the inclusions into solid and liquid steel. The number density of inclusions trapped in solid steel during one iteration is $\frac{\Delta f \mathrm{~S}}{f \mathrm{~S}} N_{i}$, where $N_{i}$ is the total number density. It is also assumed that there will not be any nucleation and growth for trapped inclusions in solid steel since no supersaturation is expected in solid steel. The coarsening of trapped inclusions is possible, but we neglect this effect for simplification. In the case of pushing of inclusions, all inclusions are pushed into residual liquid and there is no existence of inclusions in the solidified part. The pushed inclusions will undergo growth and coarsening in the residual liquid.

\section{RESULTS AND DISCUSSION}

\section{A. Precipitation of MnS Inclusions During Steel Solidification}

$\mathrm{MnS}$ inclusions are frequently found in steel grades containing sulfur. Elongated MnS inclusions increase the hydrogen-induced cracking susceptibility in steels exposed to aqueous $\mathrm{H}_{2} \mathrm{~S}$ environments. ${ }^{[47]} \mathrm{MnS}$ inclusions could initiate pitting corrosion of stainless steels in environments containing chloride ${ }^{[48]} \mathrm{MnS}$ could also have some positive effect on properties of steels. In free-cutting steel, MnS plays a role in improving the machinability of steel. ${ }^{[6]} \mathrm{MnS}$ could also act as a potential nucleation agent for the formation of acicular ferrite. ${ }^{[49]}$ In the present work, the precipitation of $\mathrm{MnS}$ was modeled by combining the microsegregation calculation with the KWN model. The modeling results were validated by employing the data by You et al. ${ }^{[23]}$ on solidified steel.

\section{Model parameters for $M n S$ precipitation}

According to the assessment performed by Bester and Lange, ${ }^{[50]}$ the diffusion coefficients of sulfur in liquid iron can be calculated according to the following equation:

$$
D_{s}=4.33 \times 10^{-8} \mathrm{e}^{-35,600 / \mathrm{R} T}
$$

where $D_{S}$ is the diffusion coefficient of sulfur in liquid iron, $\mathrm{R}$ is the universal gas constant, and $T$ is the temperature in Kelvin. The temperature fitting range for Eq. [26] is from the melting point of iron to $1700{ }^{\circ} \mathrm{C}$. The diffusion coefficient of nitrogen in steel can be obtained by extrapolating Eq. [26] to the temperature below the melting point.

The value of interfacial tension between steel and $\mathrm{MnS}$ has not been reported in the literature. However, Oikawa et al. ${ }^{[51]}$ estimated this value to be in the region of $0.2 \mathrm{~N} / \mathrm{m}$ by extrapolating the data on the interfacial tension between steel and $\mathrm{MnO}-\mathrm{SiO}_{2}-\mathrm{CaO}-\mathrm{MnS}$ slag. In a simulation by You et al., ${ }^{[23]} 0.2 \mathrm{~N} / \mathrm{m}$ was also employed for interfacial tension between steel and $\mathrm{MnS}$; we adopted this value.

The equation for calculating the density of liquid steel $\rho_{\text {st }}$ at various temperatures was obtained from a handbook ${ }^{[52]}$ compiled by The Iron and Steel Institute of Japan as the following equation for Fe-0.29 mass pct C:

$$
\rho_{\mathrm{st}}=8309-0.7258 T
$$

where $T$ is the temperature in Kelvin.

The model parameters for the simulation of $\mathrm{MnS}$ precipitation during solidification are shown in Table II. 
Table II. Simulation Parameters for Formation of MnS Inclusions During Solidification

\begin{tabular}{llll}
\hline Parameters & & Values & Unit \\
\hline Density of Steel & $8309-0.7258 T$ & $\mathrm{~kg} / \mathrm{m}^{3}$ & References \\
Density of MnS Inclusion & 3990 & $\mathrm{~kg} / \mathrm{m}^{3}$ & {$[52]$} \\
Molar Mass of MnS & 0.087 & $\mathrm{~kg} / \mathrm{mol}$ & {$[53]$} \\
Diffusion Coefficient of Sulfur in Steel Melts, $D_{S}$ & $D_{s}=4.33 \times 10^{-8} e^{-35,600 / \mathrm{R} T}$ & $\mathrm{~m}^{2} / \mathrm{s}$ & $\mathrm{N} / \mathrm{m}$ \\
Interfacial Tension Between MnS and Steel Melts & 0.2 & $\mathrm{~J} / \mathrm{mol}^{-3}$ & {$[53]$} \\
Solubility Product for MnS: $[\mathrm{Mn}]+[\mathrm{S}]=\mathrm{MnS}$ & $\log _{10} K_{\mathrm{MnS}}=-\frac{8750}{T}+4.63$ & {$[51]$} & $\mathrm{m}^{-3} \cdot \mathrm{s}^{-1}$ \\
Pre-exponential Factor & $10^{23}$ & {$[23,37]$} \\
\hline
\end{tabular}

Table III. Chemical Composition (in Mass Percent) of Steels Investigated by You et al. ${ }^{[23]}$

\begin{tabular}{lccccc}
\hline Sample & C & Si & Mn & S & P \\
\hline S1 & 0.22 & 0.03 & 1.40 & 0.0060 & 0.0055 \\
S2 & 0.22 & 0.03 & 1.46 & 0.0050 & 0.0048 \\
S3 & 0.21 & 0.04 & 1.50 & 0.0021 & 0.0036 \\
\hline
\end{tabular}

\section{Validation of the model for $M n S$ precipitation}

You et al. ${ }^{[23]}$ simulated the solidification process of steel using the submerged split chill tensile (SSCT) experiment. Three steels with different sulfur contents $(60,50$, and $21 \mathrm{ppm})$ were melted and solidified using the SSCT experiment. The chemical compositions of steel investigated are shown in Table III. The inclusions in the sample solidified were measured by using automated energy-dispersive X-ray spectroscopy of a scanning electron microscope. The size distribution and number density of inclusions in a defined area were determined. The effects of the cooling rate and the sulfur concentration on the precipitation of $\mathrm{MnS}$ inclusions were investigated by sampling different horizontal positions in the solid steel shell and varying sulfur concentrations in the sample, respectively.

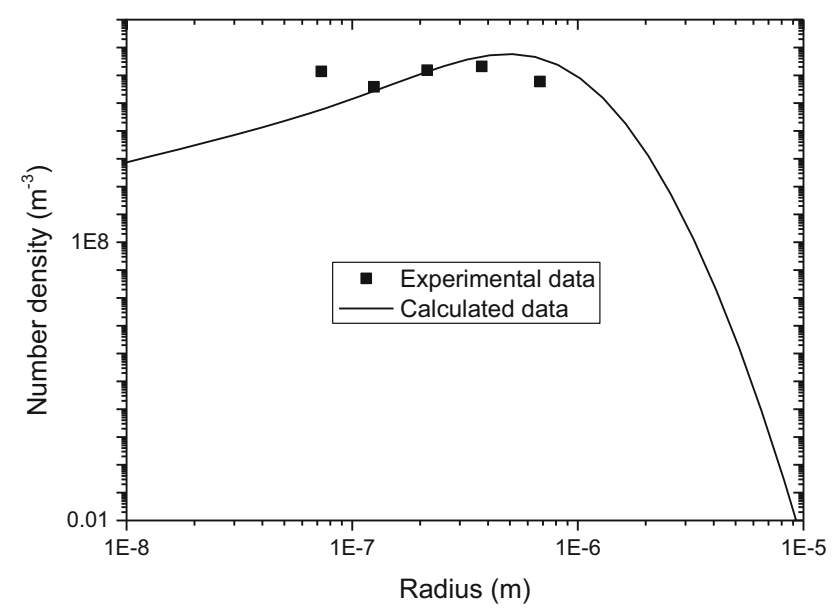

Fig. 2-Comparison between calculated and measured size distributions of $\mathrm{MnS}$ inclusions in steel sample ([S] $=60 \mathrm{ppm})$ after solidification with a cooling rate of $25.4{ }^{\circ} \mathrm{C} / \mathrm{s}$.
Figure 2 shows the comparison between the measured size distribution and calculated size distribution of $\mathrm{MnS}$ in cooled steel samples $\mathrm{S} 1$ at a cooling rate of $25.4^{\circ} \mathrm{C} / \mathrm{s}$. It can be seen that the calculated size distribution fits well with the experimental size distribution, which indicates that the present model could give a good prediction of the size distribution of $\mathrm{MnS}$ during solidification.

\section{Effect of cooling rate and sulfur concentration on $\mathrm{MnS}$ precipitation}

The cooling rate during steel solidification has an impact on the $\mathrm{MnS}$ precipitation. It was reported in a high carbon steel that the number of oxides per unit area decreased and the size of oxides increased with increasing distance from the surface of the bloom, which had solidified at the highest cooling rate. ${ }^{[54]}$ You et al. ${ }^{[23]}$ measured the size distribution of $\mathrm{MnS}$ inclusions at the different positions in the test body, which correspond to different cooling rates $\left(42.3,25.4\right.$, and $\left.13.5^{\circ} \mathrm{C} / \mathrm{s}\right)$. The calculated size distributions of $\mathrm{MnS}$ in steel sample $\mathrm{S} 1$ by the present model at cooling rates of 42.3, 25.4, and $13.5^{\circ} \mathrm{C} / \mathrm{s}$ are shown in Figure 3. As seen in Figure 3, the radius corresponding to the maximum number density $\left(R_{\mathrm{p}}\right)$ increases with decreasing cooling rates. It can be seen also that the maximum number density decreases at lower cooling rates. The number density of $\mathrm{MnS}$ decreases with decreasing cooling rates for particles with a radius less than $R_{\mathrm{p}}$, while the number density

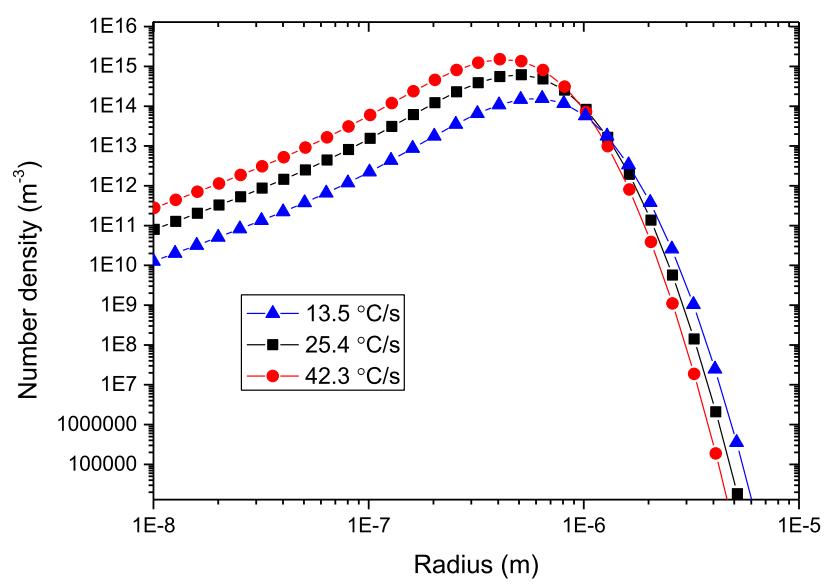

Fig. 3-Effect of cooling rate on size distribution of precipitated $\mathrm{MnS}$ in steel sample S1 after solidification. 


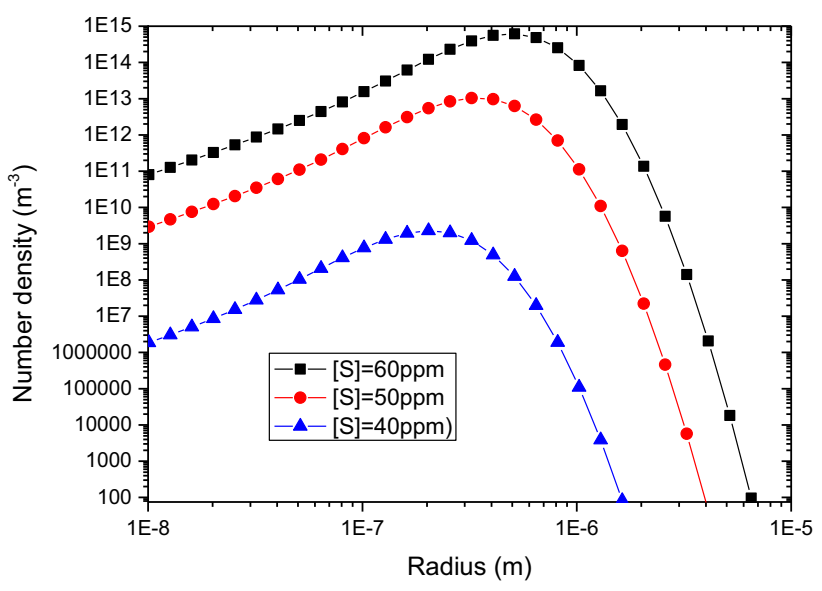

Fig. 4-Effect of sulfur concentration on size distribution of precipitated $\mathrm{MnS}$ inclusion in steel after solidification.

increases with decreasing cooling rates for particles with a radius larger than $R_{\mathrm{p}}$. This indicates a more developed coarsening of $\mathrm{MnS}$ inclusions with lower cooling rates. The present results are consistent with the results by You et al. regarding the changing trend of mean particle size with decreasing cooling rates. The tendency for variation of the number density and mean size with cooling rate is also consistent with the investigation on high-carbon steel bloom by Faraji et al. ${ }^{[54]}$

The sulfur concentration in steel could also affect the precipitation of $\mathrm{MnS}$ in steel by changing the supersaturation for nucleation. The size distributions of $\mathrm{MnS}$ for three steels with different sulfur concentrations $(60,50$, and $40 \mathrm{ppm})$ were calculated by the present model and are shown in Figure 4. It can be seen that $R_{\mathrm{p}}$ decreases for steels with lower sulfur concentration, as does the maximum number density for these steels. This is consistent with the experimental data by You et al. ${ }^{[23]}$ with respect to the changing tendency of $R_{\mathrm{p}}$ and maximum number density. However, the experimental result for steel with $20 \mathrm{ppm}$ cannot be reproduced since very few $\mathrm{MnS}$ could be precipitated according to the model calculation results. This inconsistency between model calculations and experiments could be due to the possible heterogeneous nucleation in steel samples with low sulfur concentration. There is no micrograph for inclusions reported in the work by You et al., ${ }^{[23]}$ and the possibility of heterogeneous nucleation cannot be excluded. Heterogeneous nucleation would promote the precipitation of $\mathrm{MnS}$ in samples with low sulfur concentration. However, heterogeneous nucleation was not accounted for in the present model, leading to the inconsistency of samples with low sulfur concentration. The reduced number density with lower sulfur concentrations should be attributed to the lower nucleation rate due to reduced supersaturation. According to Eq. [13], as the concentration of sulfur decreases, the growth rate of crystals also decreases, which would lead to the movement of size distribution toward a smaller radius.

\section{B. Precipitation of TiN Inclusions During Steel Solidification}

TiN is one of the most important types of inclusions in stainless steels $^{[55]}$ and bearing steels containing titanium. ${ }^{[56]}$ TiN inclusions are often observed to have sharp edges and corners in the steel matrix and can be sources of cracks in the rolling process. ${ }^{[57]} \mathrm{TiN}$ inclusions could initialize single pits, which act as cathodes $v s$ the steel, and accelerated breakdown of the passive layer in corrosive environments, such as those including chlorine ${ }^{[58]}$ Large TiN inclusions seriously affect the fatigue properties of the bearing steel. ${ }^{[56]}$ Therefore, it is strongly desirable to control the precipitation of TiN inclusions during solidification of steel. Much experimental and model work on precipitation of TiN inclusions during solidification of steel has been reported in the literature. ${ }^{[20,59-63]}$ In the present work, the precipitation kinetics of TiN was modeled by combining microsegregation calculation with the KWN model. The model calculation was validated by the experimental data by Rocabois et al. ${ }^{[20]}$ on quenched directionally solidified steel.

\section{Evaluation of model parameters}

Bester and Lange ${ }^{[50]}$ critically assessed the diffusion coefficients of nitrogen in liquid iron and obtained the following equation:

$$
D_{\mathrm{N}}=2.586 \times 10^{-7} \mathrm{e}^{-50,200 / \mathrm{R} T} \quad\left(T_{\mathrm{L}} \text { to } 1700^{\circ} \mathrm{C}\right)
$$

where $D_{\mathrm{N}}$ is the diffusion coefficient of nitrogen in liquid iron and $T$ is the temperature in Kelvin. The temperature fitting range for Eq. [28] is from the melting point of iron to $1700{ }^{\circ} \mathrm{C}$. An extrapolating procedure can be made to calculate the diffusion coefficient of nitrogen in steel below the melting point.

There is no experimental data reported for interfacial tension between TiN and steel. Nishizawa et al. ${ }^{[64]}$ estimated the interfacial tension between TiN and liquid iron to be $0.3 \mathrm{~N} / \mathrm{m}$ by employing an improved version of the Becker's model for interfacial energy calculations at liquid metal-liquid metal interfaces to calculate the total energy of interatomic bonds across an interface. Considering that there are some surface-active elements, such as oxygen and sulfur, in liquid steel, we employed an interfacial tension value of $0.28 \mathrm{~N} / \mathrm{m}$ between TiN and liquid steel for samples with low sulfur concentration. The high sulfur concentration of steel could lead to a further decrease of interfacial tension between TiN and liquid steel. The influence of interfacial tension between TiN and liquid steel on the inclusion distribution is discussed in Section II-C.

The model parameters for precipitation of TiN during solidification of steel are listed in Table IV.

2. Validation of the model for the precipitation of TiN Rocabois et al. ${ }^{[20]}$ investigated the precipitation of TiN inclusions in quenched directionally solidified steel rods $(5-\mathrm{mm}$ diameter and $300-\mathrm{mm}$ long) with a conventional vertical apparatus with a static induction coil under controlled thermal conditions. The cooling rate 
Table IV. Simulation Parameters for Formation of TiN Inclusions during Solidification

\begin{tabular}{|c|c|c|c|}
\hline Parameter & Value & Unit & References \\
\hline Density of Steel & $8309-0.7258 T$ & $\mathrm{~kg} / \mathrm{m}^{3}$ & [52] \\
\hline Density of TiN Inclusion & 5210 & $\mathrm{~kg} / \mathrm{m}^{3}$ & {$[65]$} \\
\hline Molar Mass of TiN & 0.0619 & $\mathrm{~kg} / \mathrm{mol}$ & [65] \\
\hline Diffusion Coefficient of Nitrogen in Steel Melts $D_{\mathrm{N}}$ & $D_{\mathrm{N}}=2.586 \times 10^{-7} e^{-50,200 / \mathrm{R} T}$ & $\mathrm{~m}^{2} / \mathrm{s}$ & {$[50]$} \\
\hline Interfacial Tension Between TiN and Steel Melts & 0.28 & $\mathrm{~N} / \mathrm{m}$ & [64] \\
\hline $\begin{array}{l}\text { Solubility Product of TiN: } \\
{[\mathrm{Ti}]+[\mathrm{N}]=\mathrm{TiN}}\end{array}$ & $\log _{10} K_{\mathrm{TiN}}=-\frac{14,400}{T}+4.94$ & $\mathrm{~J} / \mathrm{mol}$ & {$[38]$} \\
\hline Pre-exponential Factor & $10^{34}$ & $\mathrm{~m}^{-3} / \mathrm{s}$ & - \\
\hline
\end{tabular}

employed in their experiments was $0.37^{\circ} \mathrm{C} / \mathrm{s}$. Longitudinal and transverse cross sections containing the quenched mushy zone were analyzed using the metallographic method. The observation of the position of inclusion toward dendrites showed that TiN inclusions were pushed out of the solid-liquid front in the interdendritic regions. Two compositions of steels with low (25 ppm) and high (440 ppm) sulfur concentrations were investigated. The chemical compositions of these two steels are shown in Table V. The sizes of the TiN inclusions at different stages of the solidification for low sulfur steel were measured.

The precipitation of TiN during solidification was simulated by the present model. The model parameters in Table IV were employed for the calculation of low sulfur (25 ppm) steel. It is assumed that all inclusions were pushed out of solid steel during solidification.

The calculated mean sizes of TiN inclusions are shown in Figure 5. For comparison, the experimental mean sizes of TiN from Rocabois et al. ${ }^{[20]}$ are also shown in Figure 5. It can be seen from the figure that the growth is predicted to start already at higher temperatures and continue above the plateau level measured by Rocabois et al. ${ }^{[20]}$ Generally, the calculated mean sizes of TiN inclusions at different temperatures were in reasonable agreement with the experimental data from Rocabois et al. ${ }^{[20]}$ This indicates that the present model could give a good prediction of precipitation characteristics of TiN inclusion during solidification.

The size distributions of inclusion at different temperatures were calculated and are shown in Figure 6. It can be seen that the total distribution shifts toward the larger radius as the solidification proceeds. The peak -value radius of TiN inclusion increases with decreasing temperature, while the maximum and total number density only change slightly. All size distributions can be found to obey lognormal distribution, which is a common characteristic for distribution after nucleation and growth. ${ }^{[2,4,29-32]}$ These characteristics of size distribution can be explained with competitive nucleation and growth of TiN inclusions. The growth and coarsening of inclusion particles would lead to larger particles as the solidification proceeds. The lowering of number density due to the coarsening is compensated by the continuous nucleation of inclusion particles, so the maximum and total number density remains nearly invariant. Rocabois et al. ${ }^{[20]}$ also found that the number density $N_{\mathrm{V}}$ remains nearly constant during the solidification with a value of around $3.3 \times 10^{12} / \mathrm{m}^{3}$. A comparison could be made between the calculated and experimental results on number density. The calculated maximum number density in the present work is also almost constant during solidification. The calculated maximum number density $\left(10^{13} \mathrm{~m}^{-3}\right)$ is somewhat higher than the experimental data $\left(3.3 \times 10^{12} \mathrm{~m}^{-3}\right)$. But, considering that the number density values are from scanning electron microscope examinations on sections, the difference between calculated and experimental data is still reasonable.

\section{Effect of interfacial tension between TiN and liquid} steel on precipitation of TiN

Oxygen and sulfur are well-known surface-active elements in liquid steel. The surface tension of liquid steel can be decreased with increasing concentrations of oxygen and sulfur. In experiments by Rocabois et al., ${ }^{[20]}$ two steel compositions with low and high sulfur concentration were investigated. The interfacial tensions between TiN and two liquid steel compositions should differ from one another.

Since the information on the interfacial tension between TiN and liquid steels with different sulfur concentrations is scarce, a sensitivity analysis on the effect of the interfacial tension and sulfur concentration on the precipitation of TiN was conducted.

The final size distributions of TiN for steels were calculated with varying interfacial tensions between TiN and liquid steels $(\gamma=0.28,0.275,0.27,0.26$, and $0.25 \mathrm{~N} /$ $\mathrm{m})$. The other parameters in Table IV were employed for calculation. The size distributions of TiN with varying interfacial tension are shown in Figure 7 . It can be seen that the maximum number density and peak-value radius of TiN inclusions varied with decreasing interfacial tension from 0.28 to $0.25 \mathrm{~N} / \mathrm{m}$. As the interfacial tension decreases from 0.28 to $0.27 \mathrm{~N} / \mathrm{m}$, the peak-value radius of TiN decreases, while the maximum number density increases. The further decrease of interfacial tension from 0.27 to $0.25 \mathrm{~N} / \mathrm{m}$ only produces a slight change of peak-value radius and maximum number density. Rocabois et al. ${ }^{[20]}$ also observed in their experiments that the number density of samples with high sulfur concentration is higher than that of samples with low sulfur concentration. The mean sizes of TiN in experimental samples showed no large difference, but the mean sizes calculated by their model showed a decrease with increasing sulfur concentration. The increase of the maximum number density in size distribution with decreasing interfacial tension could be attributed to the enhanced nucleation due to the lower energy barrier for homogeneous nucleation, as shown in Eq. [12]. The decrease of the peak-value 
Table V. Compositions of Steels (in Mass Percent) Investigated by Rocabois ${ }^{[20]}$

\begin{tabular}{lccccccrrr}
\hline Steel Sample & Mn & Si & Al & Cr & Ti & O & S & N & C \\
\hline High S & 0.002 & 0.315 & 0.069 & 0.691 & 0.092 & 0.0016 & 0.0440 & 0.0129 & 0.392 \\
Low S & 0.002 & 0.315 & 0.069 & 0.691 & 0.092 & 0.0018 & 0.0025 & 0.0122 & 0.403 \\
\hline
\end{tabular}

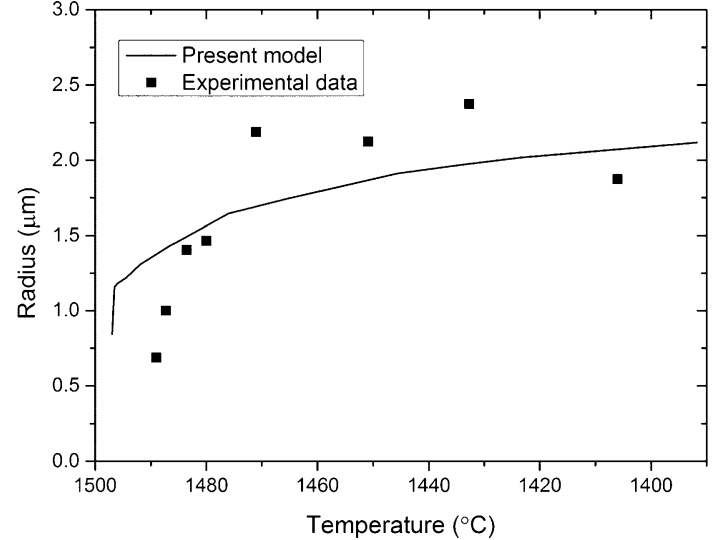

Fig. 5-Comparison between calculated and measured mean radii of TiN precipitated at different stages of solidification for steel with sulfur concentration of $25 \mathrm{ppm}$ at $0.37^{\circ} \mathrm{C} / \mathrm{s}$ cooling rate $\mathrm{e}^{[20]}$

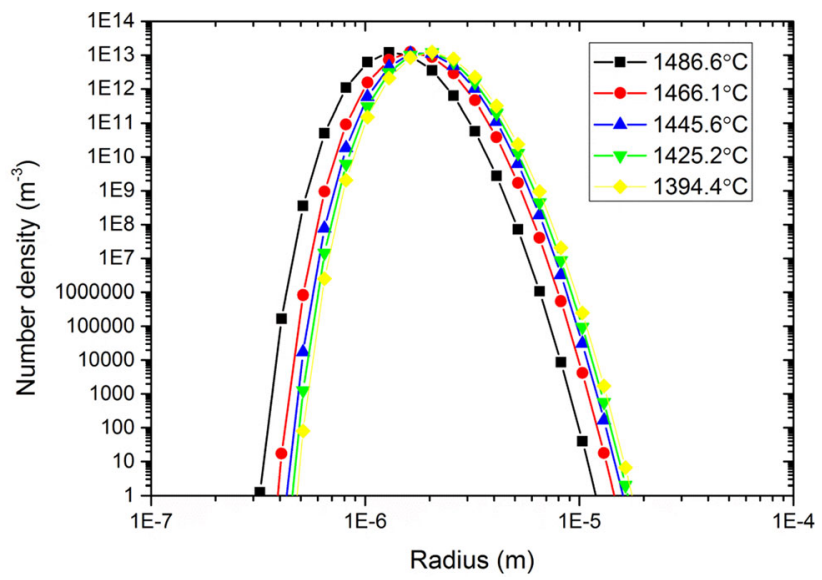

Fig. 6-Size distributions of TiN inclusion precipitated at different temperatures for steel with sulfur concentration of $25 \mathrm{ppm}$.

radius of $\mathrm{TiN}$ inclusions with decreasing interfacial tension should be due to the suppression of coarsening. The coarsening (Ostwald ripening) of particles is often interpreted by employing Lifshitz-Sloyzov-Wagner theory. ${ }^{[66,67]}$ If it is assumed that the ripening during solidification is controlled by diffusion, we can obtain

$$
\bar{d}^{3}-\bar{d}_{0}^{3}=k t=\frac{64 D \sigma_{\mathrm{SL}} V_{\mathrm{S}} c_{0}}{9 \mathrm{R} T} t
$$

where $\bar{d}$ and $\bar{d}_{0}$ are the mean crystal size at time $t$ and at the beginning of coarsening, respectively; $D$ is the effective diffusion coefficient; $\sigma_{\mathrm{SL}}$ is the interfacial tension between solid and liquid; $V_{\mathrm{S}}$ is the molar volume of crystal; and $c_{0}$ is the mass concentration of mobile species in liquid equilibrated with a crystal with infinite large size.

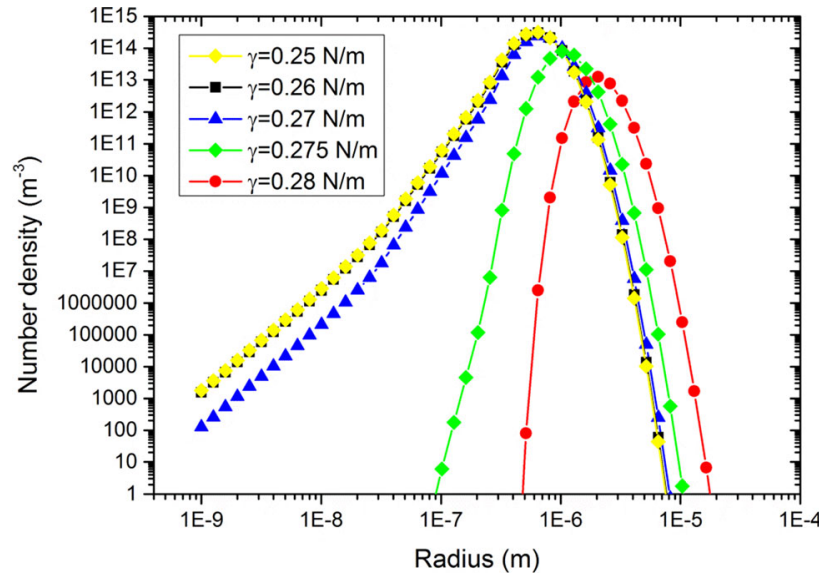

Fig. 7-Effect of interfacial tension between TiN and steel on the size distribution of precipitated TiN after solidification of steel.

According to Eq. [29], the coarsening rate $k$ is directly proportional to the interfacial tension $\sigma_{\mathrm{SL}}$. Consequently, a decrease in $\sigma_{\mathrm{SL}}$ leads to a corresponding relative decrease in the value of $k$. The decrease of peak-value radius with decreasing interfacial tension should be attributed to the suppressed coarsening.

As seen in Figure 7, the size distribution of TiN becomes wider also with decreasing interfacial tension. All these findings indicate that the size distribution of inclusions is very sensitive to interfacial tension between inclusion and steel. Consequently, in order to make more detailed calculations in the future, it might be relevant to direct more research using experimental techniques toward clarifying that aspect.

\section{Effect of cooling rates on the precipitation of TiN}

The cooling condition has an impact on the precipitation of TiN particles from steel during solidification. ${ }^{[7]}$ Sage and Cochrane ${ }^{[59]}$ established an inverse linear relationship between the size of $\mathrm{TiN}$ particles and the logarithmic cooling rate during and after solidification. Stock et al. ${ }^{[60]}$ confirmed this relationship by using their data for higher cooling rates. Although Rocabois et al.$^{[20]}$ only investigated the TiN precipitation at one cooling rate $\left(0.37{ }^{\circ} \mathrm{C} / \mathrm{s}\right)$, it will be interesting to investigate effect of different cooling rates by the model simulation.

The TiN precipitations at three cooling rates $(0.37$, 3.7 , and $37^{\circ} \mathrm{C} / \mathrm{s}$ ) for a low $\mathrm{S}$ steel sample whose composition is shown in Table $\mathrm{V}$ during solidification were simulated by using the present model. The size distributions of TiN inclusions precipitated from samples cooled at different rates are shown in Figure 8. As seen in Figure 8, the size distributions at cooling rates of 3.7 and $37^{\circ} \mathrm{C} / \mathrm{s}$ have distinct characteristics that differ 


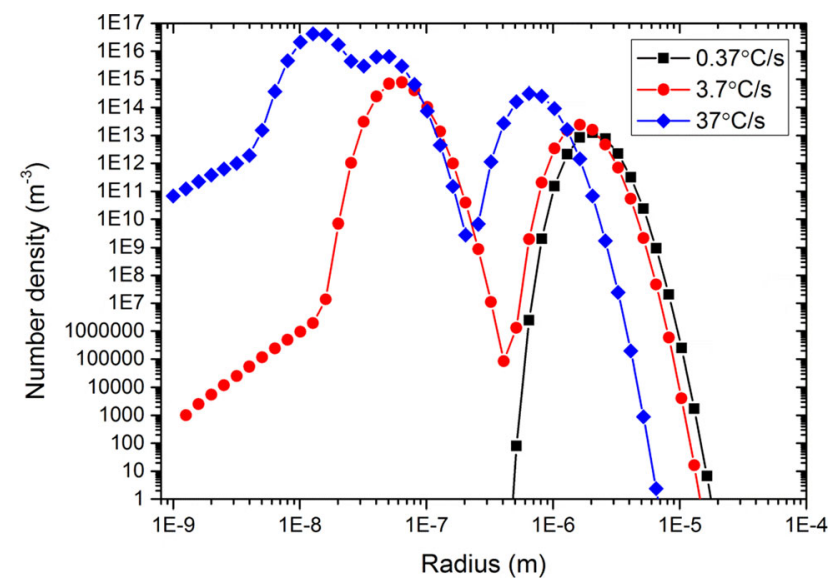

Fig. 8-Effect of cooling rates on the size distribution of TiN after solidification of low $\mathrm{S}$ steel sample.

from those at a cooling rate of $0.37{ }^{\circ} \mathrm{C} / \mathrm{s}$. The distribution at $0.37{ }^{\circ} \mathrm{C} / \mathrm{s}$ basically follows a lognormal distribution, while the distributions at higher cooling rates exhibit bimodal distributions. This kind of bimodal distribution for $\mathrm{TiN}$ inclusions was also observed by Ohta and Suito ${ }^{[61]}$ in Fe-1.5 pet Mn-0.05 pet C-0.1 pet Ti alloys and Stock et al. ${ }^{[60]}$ in a low-carbon steel. It can be also seen in Figure 8 that the size distribution curves move toward lower radius positions, indicating that the size of TiN precipitations decreases with increasing cooling rates. The mean radius values at the three cooling rates $\left(0.37,3.7\right.$, and $\left.37^{\circ} \mathrm{C} / \mathrm{s}\right)$ are $5.42,0.107$, and $0.0229 \mu \mathrm{m}$, respectively. This kind of cooling rate dependence of TiN size has been reported by many researchers. ${ }^{[59,60]}$ Meanwhile, the maximum number density in size distribution curves increases with increasing cooling rates, which is also in line with the size distribution previously reported.

Calculating the microsegregation of titanium and nitrogen at different cooling rates should be useful for interpreting the results of the calculated size distributions. Figure 9 shows the calculated $\mathrm{Ti}$ and $\mathrm{N}$

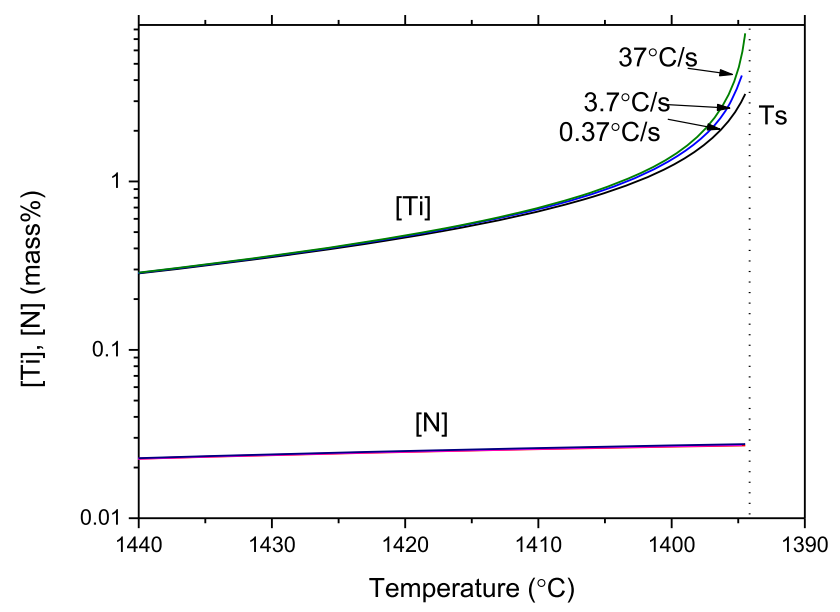

Fig. 9-Calculated $\mathrm{Ti}$ and $\mathrm{N}$ concentration in the interdendritic liquid during solidification of low $\mathrm{S}$ steel sample.

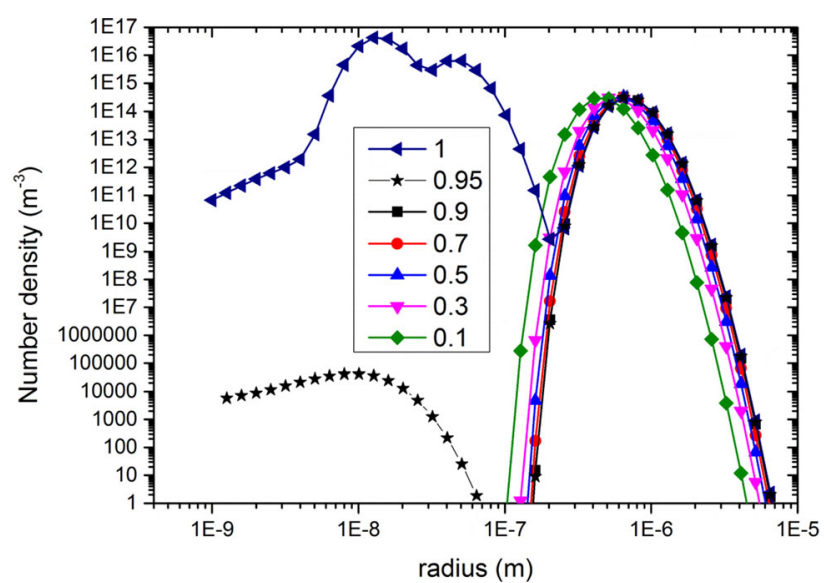

Fig. 10-Calculated size distributions of TiN at different solidification fractions with a cooling rate of $37^{\circ} \mathrm{C} / \mathrm{min}$.

concentration using the Ohnaka model ${ }^{[17]}$ in the interdendritic liquid steel during solidification of the low $\mathrm{S}$ steel sample shown in Table V. It can be seen that there is a rapid increase of $\mathrm{Ti}$ concentration near the solidus temperature. This increase becomes more significant as the cooling rate increases. It is presumed that the nucleation rate at the final stage of solidification is so high that many smaller particles form, which leads to the second logarithm normal peak. The calculated size distributions of TiN at different solidification fractions $\left(f_{\mathrm{s}}\right)$ with a cooling rate of $37^{\circ} \mathrm{C} / \mathrm{min}$ are shown in Figure 10. It can be seen that the bimodal distributions only appear after solidification proceeds at $f_{\mathrm{s}}=0.95$. This supports our presumption that the bimodal distribution should be due to the high nucleation rate at high solidification fraction. The decreased size of precipitated TiN particles at a higher cooling rate should be due to the lack of sufficient coarsening. The increased maximum number density of TiN particles observed in our calculation at high cooling rates also supports the notion that the coarsening is weaker than that at lower cooling rates.

\section{SUMMARY}

1. A kinetic model for evolution of inclusion size distribution during solidification combining microsegregation calculation with the KWN model was proposed in this work.

2. The model was applied to simulate the precipitation of $\mathrm{MnS}$ during solidification. The calculated size distributions of precipitated $\mathrm{MnS}$ are compared with experimental data by You et al. The comparison showed a good agreement between calculated and experimental size distributions.

3. The effects of cooling rate and sulfur concentration on precipitation of $\mathrm{MnS}$ were investigated by model calculations. As cooling rates decrease, the radius corresponding to the maximum number density $\left(R_{\mathrm{p}}\right)$ increases and the maximum number density of $\mathrm{MnS}$ 
decreases. Both $R_{\mathrm{p}}$ and the maximum number density decrease for steel with lower sulfur concentration.

4. Further application of the present model in precipitation of TiN was validated by the unidirectional solidification data from Rocabois et al. ${ }^{[20]}$ The calculated mean sizes of precipitated $\mathrm{Ti}$ inclusions are in good agreement with the experimental data.

5. The effect of variation of interfacial tension between TiN and steel due to the sulfur content change on the TiN precipitation was investigated by the model calculation. It was found that the peak-value radius of TiN decreases and the maximum number density increases with decreasing interfacial tension, which was attributed to enhanced nucleation and suppressed coarsening. The size distribution of TiN becomes wider also with decreasing interfacial tension. The size distribution of TiN inclusions is very sensitive to interfacial tension between inclusion and steel.

6. The effect of cooling rates on the TiN precipitation was also investigated by model calculations. The size distribution of TiN at a cooling rate of $0.37 \mathrm{~K} / \mathrm{s}$ basically follows a lognormal distribution, while size distributions at high cooling rates exhibit bimodal distributions. The existence of the second logarithm normal peak could be due to the extreme high supersaturation at the final stage of solidification leading to the precipitations of many smaller particles. The size distribution curves move toward lower radius position, indicating that the size of TiN precipitations decreases with increasing cooling rates. The decreased size of precipitated TiN particles at higher cooling rates should be due to the lack of sufficient coarsening

\section{ACKNOWLEDGMENTS}

The financial support from the Academy of Finland for Genome of Steel (Grant No. 311934) is gratefully acknowledged.

\section{OPEN ACCESS}

This article is licensed under a Creative Commons Attribution 4.0 International License, which permits use, sharing, adaptation, distribution and reproduction in any medium or format, as long as you give appropriate credit to the original author(s) and the source, provide a link to the Creative Commons licence, and indicate if changes were made. The images or other third party material in this article are included in the article's Creative Commons licence, unless indicated otherwise in a credit line to the material. If material is not included in the article's Creative Commons licence and your intended use is not permitted by statutory regulation or exceeds the permitted use, you will need to obtain permission directly from the copyright holder. To view a copy of this licence, visit http://creativec ommons.org/licenses/by/4.0/.

\section{FUNDING}

Open access funding provided by University of Oulu including Oulu University Hospital.

\section{REFERENCES}

1. L. Holappa and O. Wijk: in Treatise on Process Metallurgy, Volume 3: Industrial Processes, S. Seetharaman, A. McLean, R. Guthrie, and S. Sridhar, eds., 2014, pp. 347-72.

2. L. Zhang and W. Pluschkell: Ironmak. Steelmak., 2003, vol. 30 (2), pp. 106-10.

3. P.R. Scheller and Q. Shu: Steel Res. Int., 2014, vol. 85 (8), pp. $1310-16$.

4. Z. Deng, Y. He, J. Liu, B. Yan, Y. Yang, and A. McLean: Metals, 2019, vol. 9 (10), p. 1091

5. Q. Tian, G. Wang, Y. Zhao, J. Li, and Q. Wang: Metall. Mater. Trans. B, 2018, vol. 49B, pp. 1149-64.

6. H. Sui, L. Wang, Q. Wang, H. Wang, D. Che, J. Li, and K. Chou: Steel Res. Int., 2018, vol. 89 (10), p. 1800179.

7. M.T. Nagata, J.G. Speer, and D.K. Matlock: Metall. Mater. Trans. A, 2002, vol. 33A, pp. 3099-10.

8. M. Suzuki, R. Yamaguchi, K. Murakami, and M. Nakada: ISIJ Int., 2001, vol. 41 (3), pp. 247-56.

9. J. Kunze, C. Mickel, M. Leonhardt, and S. Oswald: Steel Res., 1997, vol. 68 (9), pp. 403-08.

10. D. You, S.K. Michelic, P. Presoly, J. Liu, and C. Bernhard: $\mathrm{Me}$ tals, 2017, vol. 7 (11), p. 460.

11. D. You, S.K. Michelic, C. Bernhard, D. Loder, and G. Wieser: ISIJ Int., 2016, vol. 56 (10), pp. 1770-78.

12. S.K. Choudhary and A. Ghosh: ISIJ Int., 2009, vol. 49 (12), pp. $1819-27$.

13. S. Nurmi, S. Louhenkilpi, and L. Holappa: Steel ResInt., 2009, vol. 80 (6), pp. 436-40.

14. Z. Ma and D. Janke: ISIJ Int., 1998, vol. 38 (1), pp. 46-52.

15. D. You, C. Bernhard, G. Wieser, and S. Michelic: Steel Res. Int., 2016, vol. 87 (7), pp. 840-49.

16. Y.H. Shin, K.S. Oh, and E.P. Yoon: ISIJ Int., 2001, vol. 41, pp. $158-63$.

17. I. Ohnaka: Trans. ISIJ, 1986, vol. 26 (12), pp. 1045-51.

18. T.W. Clyne and W. Kurz: Metall. Trans. A, 1981, vol. 12A, pp. 965-71.

19. H.D. Brody and M.C. Flemings: Trans. TMS-AIME, 1966, vol. 236, p. 615 .

20. P. Rocabois, J. Lehmann, H. Gaye, and M. Wintz: J. Cryst. Growth, 1999, vol. 198, pp. 838-43.

21. H. Gaye, P. Rocabois, J. Lehmann, and M. Bobadilla: Steel Res., 1999, vol. 70 (8-9), pp. 356-61.

22. J. Lehmann, P. Rocabois, and H. Gaye: J. Non-Cryst. Solids, 2001, vol. 282 (1), pp. 61-71.

23. D. You, S.K. Michelic, G. Wieser, and C. Bernhard: J. Mater. Sci., 2017, vol. 52 (3), pp. 1797-12.

24. D. You, S. Michelic, and C. Bernhard: Metals, 2018, vol. 8 (6), p. 452.

25. J.S. Langer and K. Schwartz: Phys. Rev. A, 1980, vol. 21 (3), p. 948.

26. R. Kampmann and R. Wagner: Decomposition of Alloys: the Early Stages, 1983, pp. 91-103.

27. Z.K. Low, T. Chaise, D. Bardel, S. Cazottes, P. Chaudet, M. Perez, and D. Nelias: Acta Mater., 2018, vol. 156, pp. 31-42.

28. F. Fazeli, C.W. Sinclair, and T. Bastow: Metall. Mater. Trans. A, 2008, vol. 39A, p. 2297.

29. S.N. Samaras: Modell. Simu. Mater. Sci. Eng., 2006, vol. 14 (8), p. 1271.

30. J.D. Robson: Acta Mater., 2004, vol. 52 (15), pp. 4669-76.

31. J.D. Robson: Acta Mater., 2004, vol. 52 (6), pp. 1409-21.

32. O.R. Myhr and Ø. Grong: Acta Mater., 2000, vol. 48 (7), pp. $1605-15$.

33. J. Zhang and H.G. Lee: ISIJ Int., 2004, vol. 44 (10), pp. 1629-38.

34. H. Lei, K. Nakajima, and J.C. He: ISIJ Int., 2010, vol. 50 (12), pp. $1735-45$. 
35. Y.M. Won and B.G. Thomas: Metall. Mater. Trans. A, 2001, vol. 32A, pp. 1755-67.

36. R. Diederichs and W. Bleck: Steel Res. Int., 2006, vol. 77 (3), pp. 202-209.

37. G. Xia: Ph.D. Dissertation, Montanuniversität Leoben, Leoben, 1992.

38. H. Wada and R.D. Pehlke: Metall. Trans. B, 1985, vol. 16B, pp. $815-22$.

39. D. Turnbull: J. Chem. Phys., 1952, vol. 20 (3), pp. 411-24.

40. H.B. Aaron, D. Fainstein, and G.R. Kotler: J. Appl. Phys., 1970, vol. 41 (11), pp. 4404-10.

41. S.V. Patankar: Numerical Heat Transfer and Fluid Flow, Hemisphere, Washington, DC, 1980.

42. T. Nakaoka, S. Taniguchi, K. Matsumoto, and S.T. Johansen: ISIJ Int., 2001, vol. 41 (10), pp. 1103-11.

43. M. Smoluchowski: Z. Phys. Chem., 1917, vol. 92, p. 127.

44. H. Shibata, H. Yin, S. Yoshinaga, T. Emi, and M. Suzuki: ISIJ Int., 1998, vol. 38 (2), pp. 149-56.

45. H. Ohta and H. Suito: ISIJ Int., 2006, vol. 46 (4), pp. 472-79.

46. W. Yamada, T. Matsumiya, and A. Ito: Proc. 6th Int. Iron Steel Congr., Nagoya, Japan, 1990, pp. 618-25.

47. T.Y. Jin, Z.Y. Liu, and Y.F. Cheng: Int. J. Hydrogen Energy, 2010, vol. 35 (15), pp. 8014-21.

48. P. Schmuki, H. Hildebrand, A. Friedrich, and S. Virtanen: Corros. Sci., 2005, vol. 47 (5), pp. 1239-50.

49. I. Madariaga and I. Gutierrez: Acta Mater., 1999, vol. 47 (3), pp. 951-60.

50. H. Bester and K.W. Lange: Arch. Eisenhüttenwes., 1972, vol. 43 (3), pp. 207-13.

51. K. Oikawa, H. Ohtani, K. Ishida, and T. Nishizawa: ISIJ Int., 1995, vol. 35 (4), pp. 402-08.

52. K. Watanabe, K. Ogino, and Y. Tsu: Handbook of Physico-Chemical Properties at High Temperatures, The Iron and Steel Institute of Japan, Tokyo, 1988, p. 11.
53. Alabandite Mineral Data, http://webmineral.com/data/Alabandit e.shtml\#.XnI3gflHDHR, accessed March 18, 2020.

54. M. Faraji, D.P. Wilcox, R. Thackray, A.A. Howe, I. Todd, and P. Tsakiropoulos: Metall. Mater. Trans. B, 2015, vol. 46B, pp. 24902502.

55. H. Yan, H. Bi, X. Li, and Z. Xu: Mater. Charact., 2008, vol. 59, pp. 1741-46.

56. T. Uesugi: Trans. ISIJ., 1986, vol. 26 (7), pp. 614-20.

57. A. Melander: Int. J. Fatigue, 1997, vol. 19 (1), pp. 13-24.

58. M.B. Leban and R. Tisu: Eng. Failure Anal., 2013, vol. 33, pp. $430-38$.

59. A.M. Sage and R.C. Cochrane: The Development of a Weldable Normalized Vanadium Titanium Structural Steel, Vanadium International Technical Committee, Vanitec, 1988.

60. J. Stock, C.M. Enloe, R.J. O'Malley, and K.O. Findley: AIST Trans., 2014, vol. 11 (4), pp. 180-87.

61. H. Ohta and H. Suito: OISIJ Int., 2007, vol. 47 (2), pp. 197-206.

62. S. Roy, S. Patra, S. Neogy, A. Laik, S.K. Choudhary, and D. Chakrabarti: Metall. Mater. Trans. A, 2012, vol. 43A, pp. 184560.

63. M.H. Lee and J.H. Park: Metall. Mater. Trans. B, 2018, vol. 49B, pp. 877-93.

64. T. Nishizawa, I. Ohnuma, and K. Ishida: J. Phase Equilib., 2001, vol. 22 (3), p. 269

65. W.M. Haynes: CRC Handbook of Chemistry and Physics, 97th ed., CRC Press, Boca Raton, FL, 2016, p. 92.

66. I.M. Lifshitz and V.V. Slyozov: J. Phys. Chem. Solids, 1961, vol. 19 , pp. $35-50$.

67. C. Wagner: Ber. Bunsenges. Phys. Chem., 1961, vol. 65, pp. 58191.

Publisher's Note Springer Nature remains neutral with regard to jurisdictional claims in published maps and institutional affiliations. 